\title{
Nonlinear Analysis of Offshore Wind Towers in Prefabricated Segments of Prestressed Fibre Reinforced Concrete
}

\author{
Fabio P. Figueiredo ${ }^{1[0000-0001-5560-4969]}$ Joaquim A. O. Barros ${ }^{1[0000-0003-1528-757 \mathrm{X}]}$ and A. \\ Ventura-Gouveia ${ }^{2[0000-0002-1057-8733]}$ \\ ${ }^{1}$ University of Minho, Portugal \\ ${ }^{2}$ Polytechnic Institute of Viseu, Portugal \\ f.figueiredo@civil.uminho.pt
}

\begin{abstract}
This paper presents the nonlinear finite element analysis of a new concept of offshore wind tower made by prefabricated prestressed fibre reinforced concrete (FRC) segments that are assembled to form the final structure. Fibre reinforcement aims to eliminate conventional passive steel reinforcement in order to avoid corrosion concerns and decrease the thickness of the segments. The first stage of the design approach consists on an analytical model that optimizes the geometry of the eolic tower by considering the relevant loading cases, the properties of the developed FRC, the resisting stress levels of the constituent materials and the frequency and lateral deformability of the tower. By determining the thickness and radius along with the height of the tower, this model can provide the solution of minimum FRC volume for the eolic tower. In the second stage of the design approach, the optimum solution from the previous design stage is simulated by a finite element approach that considers the geometric and material nonlinear features. This paper describes the main relevant aspects of this design methodology.
\end{abstract}

Keywords: Fibre Reinforced Concrete, Nonlinear Finite Element, Offshore Wind Tower.

\section{Introduction}

Wind power has grown fast in the last two decades. Global wind-generation capacity has increased by thirty per cent over the past decade [1]. This type of renewable energy has become attractive not only because costs are falling, but especially because it is greener and can deliver a more environmentally friend solution. Modern wind turbines are typically a horizontal-axis machine with a three-bladed rotor mounted upwind on a tower. The tower heights of wind turbines have increased during recent years to capture the more energetic winds that occur at higher elevations. These structures can range from 60 to $200 \mathrm{~m}$.

This research investigates a new concept of offshore wind tower made by prefabricated prestressed fibre reinforced concrete (FRC) segments that are assembled to form 
the final structure. This new system allows the construction of towers of relatively low self-weight and high stiffness, which can deliver better structural behaviour than actual solutions, as well as higher durability, lower construction time, manufacturing and maintenance costs.

This paper describes the properties of the developed FRC and the finite element analyses carried out to investigate the influence of the tower's geometry and material properties of FRC on the local and global behaviour of this structure, in the context of its aimed functioning for serviceability and ultimate limit state conditions.

\section{Material Properties}

A FRC was produced according to the mixture composition given in Table 1, where W/C abbreviates water (W) to cement (C) ratio. Superplasticizer Sika 3005 (SP) has been used to assure the required self-compactibility requirements due to the low water content. A crushed granite coarse aggregate was used with a maximum aggregate size of $12 \mathrm{~mm}$. The mix included $60 \mathrm{~kg} / \mathrm{m}^{3}$ of hooked-end steel fibres of length $\left(l_{f}\right)$ and diameter $\left(d_{f}\right)$ of $33 \mathrm{~mm}$ and $0.55 \mathrm{~mm}$, respectively, aspect ratio $\left(l_{f} / d_{f}\right)$ of 60 , and tensile strength of about $1100 \mathrm{MPa}$. The fresh concrete behaviour was determined by the Abrams cone slump test in the inverted position according to EFNARC [2] recommendations. The spread diameter was approximately $590 \mathrm{~mm}$.

Table 1. Mix design of steel fibre reinforced self-compacting concrete per $\mathrm{m}^{3}$.

\begin{tabular}{lllllllll}
\hline $\begin{array}{l}\text { Cement } \\
{[\mathrm{kg}]}\end{array}$ & $\begin{array}{l}\text { Water } \\
{[\mathrm{kg}]}\end{array}$ & $\begin{array}{l}\text { W/C } \\
{[-]}\end{array}$ & $\begin{array}{l}\text { SP } \\
{[\mathrm{kg}]}\end{array}$ & $\begin{array}{l}\text { Filler } \\
{[\mathrm{kg}]}\end{array}$ & $\begin{array}{l}\text { Fine sand } \\
{[\mathrm{kg}]}\end{array}$ & $\begin{array}{l}\text { Coarse sand } \\
{[\mathrm{kg}]}\end{array}$ & $\begin{array}{l}\text { Coarse ag- } \\
\text { gregate } \\
{[\mathrm{kg}]}\end{array}$ & $\begin{array}{l}\text { Fibre } \\
{[\mathrm{kg}]}\end{array}$ \\
\hline 412 & 124 & 0.30 & 7.83 & 353 & 237 & 710 & 590 & 60 \\
\hline
\end{tabular}

Six cylinders, $150 \times 300 \mathrm{~mm}$, were tested at 28 days. The average compressive strength and modulus of elasticity were $72 \mathrm{MPa}$ and $42.15 \mathrm{GPa}$, respectively. The coefficients of variation $(\mathrm{CoV})$ were $8.23 \%$ and $0.26 \%$, respectively.

In order to assess the influence of fibre distribution and orientation, four-point notched beam bending tests were carried out according to the Italian standard [UNI$11039,2003]$ in specimens $(240 \times 60 \times 60 \mathrm{~mm}$, with a notch of $10 \mathrm{~mm}$ depth and $2 \mathrm{~mm}$ width) extracted from a shell type panel [3]. The average force versus crack tip mouth displacement (F-CTOD) for the series with fibre orientation intervals $\left[0-15^{\circ}[\right.$, $[15-$ $45^{\circ}$, $\left[45-75^{\circ}\left[\right.\right.$ and $\left[75-90^{\circ}\right]$ is represented in Fig. 1a, while the corresponding quadrilinear tensile stress vs crack normal tensile strain diagrams, obtained from the inverse analysis [4], are shown in Fig. 1b, whose defining values are included in Table 2. These diagrams will define the fracture mode I parameters used in the material nonlinear analysis carried out in this work. 


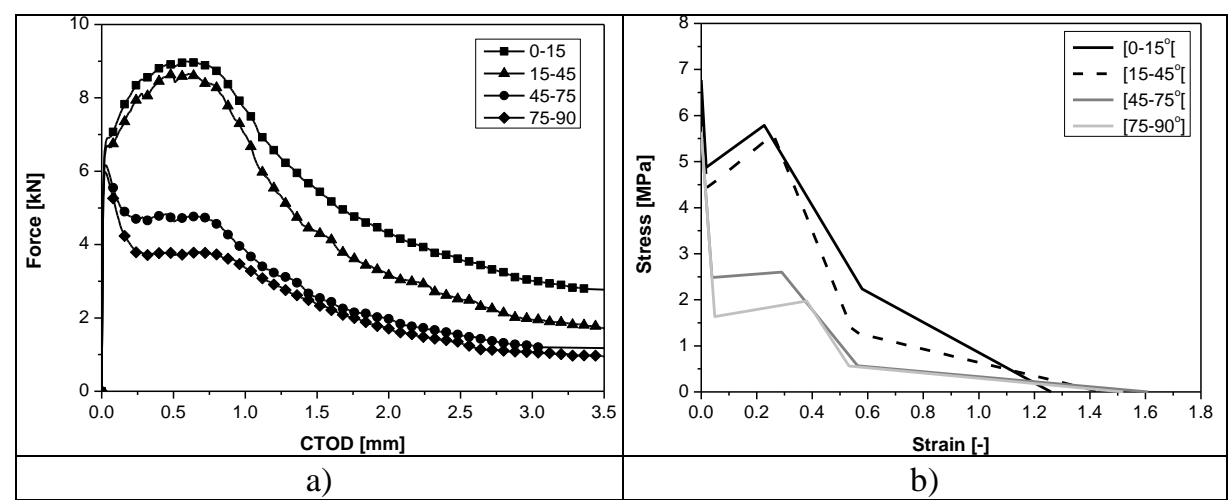

Fig. 1. a) Force vs crack tip mouth displacement response for the series of fibre orientation: [0$15^{\circ}\left[\right.$, $\left[15-45^{\circ}\left[,\left[45-75^{\circ}\left[\right.\right.\right.\right.$ and $\left[75-90^{\circ}\right]$, and b) corresponding post-cracking tensile stressstrain relationships obtained by inverse analysis.

Table 2. Mix design of steel fibre reinforced self-compacting concrete per $\mathrm{m}^{3}$.

\begin{tabular}{lllllllll}
\hline$\beta$ & $\alpha_{1}$ & $\alpha_{2}$ & $\alpha_{3}$ & $\xi_{1}$ & $\xi_{2}$ & $\xi_{3}$ & $f_{c t}$ & $G_{f}^{I}$ \\
& {$[-]$} & {$[-]$} & {$[-]$} & {$[-]$} & {$[-]$} & {$[-]$} & {$[\mathrm{MPa}]$} & {$[\mathrm{N} / \mathrm{mm}]$} \\
\hline$\left[0-15^{\circ}\right]$ & 0.72 & 0.85 & 0.33 & 0.014 & 0.18 & 0.46 & 6.77 & 6.00 \\
{$\left[15-45^{\circ}\right]$} & 0.68 & 0.86 & 0.20 & 0.014 & 0.18 & 0.38 & 6.50 & 5.10 \\
{$\left[45-75^{\circ}\right]$} & 0.44 & 0.46 & 0.10 & 0.024 & 0.18 & 0.35 & 5.65 & 2.70 \\
{$\left[75-90^{\circ}\right]$} & 0.29 & 0.35 & 0.10 & 0.032 & 0.25 & 0.35 & 5.64 & 2.20 \\
\hline
\end{tabular}

\section{Structural Concept}

The 5MW turbine consists of a 3-bladed, $126 \mathrm{~m}$ diameter rotor, pitch regulated constant speed turbine. The support structure is a monopole with a hub height of $90 \mathrm{~m}$ above mean sea level and $20 \mathrm{~m}$ below the sea level. The tower is assembled by stacking ten prefabricated prestressed fibre reinforced concrete segments measuring $11 \mathrm{~m}$ each. Fig. 2 shows the schematic representation of the offshore wind turbine and the applied loads considered in this study. 


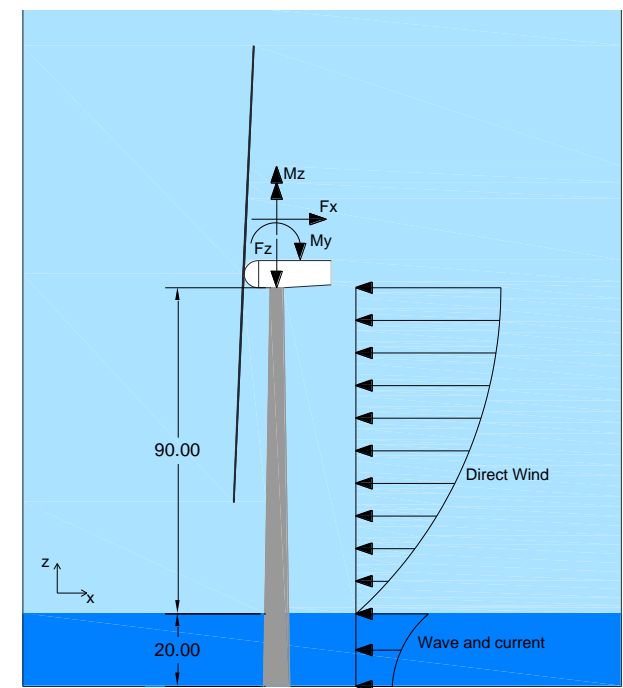

Fig. 2. Tower with the linear variation of cross-sectional diameter, thickness, and the applied loads (dimensions in $\mathrm{m}$ ).

The geometry of the tower was defined by a simplified optimisation approach [5] so that the material in use and the stresses in the structure do not exceed a maximum level. The prestressing force applied in each segment was assumed equal to $5 \%$ of the concrete compressive strength. An algorithm to find the best linear variation of tower diameter, $D(z)$, and thickness, $t(z)$, was implemented in a code written in Python. The program analyses different cases, i.e. it varies the tower diameter and thickness, to find the optimised solution for the problem. A case is considered a candidate solution only if all sections of the tower are satisfied in terms of strength and geometry restrictions criteria.

The diameter of the tower, after the optimisation process, was $3.6 \mathrm{~m}$ and $7.2 \mathrm{~m}$ at the top and bottom respectively. The thickness of the tower wall varies linearly from $0.4 \mathrm{~m}$ at the top to $0.6 \mathrm{~m}$ at the bottom of the tower.

An initial estimation of a wind tower loading, including the major loads it will withstand during its design life, is a significant requirement for engineering practitioners. In this respect, a simplified approach for the design of support structures for offshore wind turbines is adopted in this paper. The loads considered herein consist of forces acting on the top of the structure due to wind passing throughout the rotor, wind pressure on the tower structure, waves slamming the tower, and loads produced by water currents on the tower structure (see Fig. 2). However, other load cases should be considered in the final design, such as fatigue installation and transportation, control system faults, maintenance and repair and testing. Further discussions on these cases are available in $[1,6]$.

Since it was not possible to obtain precise information about loads from turbine wind towers manufacturers, they were extrapolated from a $3 \mathrm{MW}$ wind turbine [7] and presented in Table 3. The axial forces acting on the tower are the prestressing and 
gravitational loads. The wind pressure on the tower, wave and current loads were applied as shown in Fig. 2. The wind profile was calculated using the following equation:

$$
f_{w i}(z)=0.5 C_{a} \rho_{a i r} D(z) u(z)^{2}
$$

where $f_{w i}[\mathrm{~N} / \mathrm{m}]$ is the wind load per unit of length; $\rho_{\text {air }}\left[\mathrm{kg} / \mathrm{m}^{3}\right]$ is the density of air, $C_{a}$ $[-]$ is the aerodynamic drag coefficient (shape, surface dependent), $D(z)[\mathrm{m}]$ is the diameter of the tower cross-section at elevation $z$ and $u(z)[\mathrm{m} / \mathrm{s}]$ is the mean wind speed at elevation $z$. The wave and current loads were obtained using the semiempirical Morison's equation:

$$
f_{M}(z)=f_{i}(z)+f_{d}(z)
$$

where the first term $f_{i}(z)$ represents the hydrodynamic inertial load $[\mathrm{N} / \mathrm{m}]$ and the second term $f_{d}(z)$ is the hydrodynamic drag load $[\mathrm{N} / \mathrm{m}]$. More information can be found elsewhere [5].

Table 3. 5 MW wind turbine loads.

\begin{tabular}{lll}
\hline Parameter & SLS & ULS \\
\hline Horizontal shear force Fx $(\mathrm{kN})$ & 690 & 1585 \\
Moment My $(\mathrm{kN} \mathrm{m})$ & 1600 & 3677 \\
Torque $\mathrm{Mz}(\mathrm{kN} \mathrm{m})$ & 1010 & 1789 \\
\hline
\end{tabular}

Design of wind turbines in compliance with standards requires that the structure shall satisfy ultimate, accidental, fatigue and serviceability limit state design conditions, ULS, ALS, FLS and SLS), respectively [8]. However, in this example, only the most unfavourable combination for the ULS is considered. The load combination given by DNV [8] is calculated using the following expression:

$$
F=1.0 G+1.35 E
$$

where $\mathrm{G}$ are the permanent loads and $\mathrm{E}$ are the environment loads.

\section{$4 \quad$ Finite Element Analysis}

This section describes the finite element model used in all analyses performed in this research. The models considered the geometry and loads defined in the pre-design stage explained in the previous section. The analyses were performed using the finite element package FEMIX [9].

As mentioned before, this initial study aims to investigate the influence of the tower's geometry and material properties (mainly the tensile performance) on the global behaviour of the structure. Therefore, the model does not consider the connections between the prefabricated prestressed fibre reinforced concrete (FRC) segments, which is a topic treated in another publication being prepared in parallel [10]. 
The tower was modelled using twenty-node solid finite elements with $3 \times 3 \times 3$ Gauss-Legendre integration scheme. The prestressed cables were modelled using 2 nodes perfect bounded 3D embedded cables elements with two integration points. The boundary condition was assumed fixed at the bottom. The final finite element mesh was created using 3530 elements.

The cables were modelled as a linear-elastic material with Poison's coefficient equal to 0.2 and elasticity modulus of $200 \mathrm{GPa}$. The number of cables in each prefabricated segment was variable. It was defined so that the applied prestress force was $5 \%$ of the concrete compressive strength.

The behaviour of the FRC was modelled using the 3D multi-directional fixed smeared crack model available in FEMIX 4.0, see Ventura-Gouveia [11] for more information. The fracture mode I in this model is simulated by a quadrilinear tensilesoftening diagram, whose defining values are provided in Table 2.

Five loads cases and two loads combinations were considered. Initially, selfweight, prestresses forces, nacelle and rotor mass were applied to the structure. Next, wind turbine, direct wind, current and waves forces were introduced in small steps up to the stage where the ultimate limit state capacity is reached.

Fibre orientation can significantly influence the tensile and bending behaviours of FRC. Therefore, four analyses considering only the material non-linear behaviour were performed to investigate the impact of fibre orientation on tower behaviour. The models have the same geometry (as defined in the previous section), mesh, loads and boundary conditions. The only difference between the four models was the concrete tensile behaviour, which was changed according to the data presented in Table 2. Fig. 3 shows the results of the comparison between the four models considering the fracture mode I parameters for FRC with fibre orientations in the intervals: $\left[0-15^{\circ}[,[15-\right.$ $45^{\circ}\left[\right.$, $\left[45-75^{\circ}\left[\right.\right.$ and $\left[75-90^{\circ}\right]$ (see Table 2). 


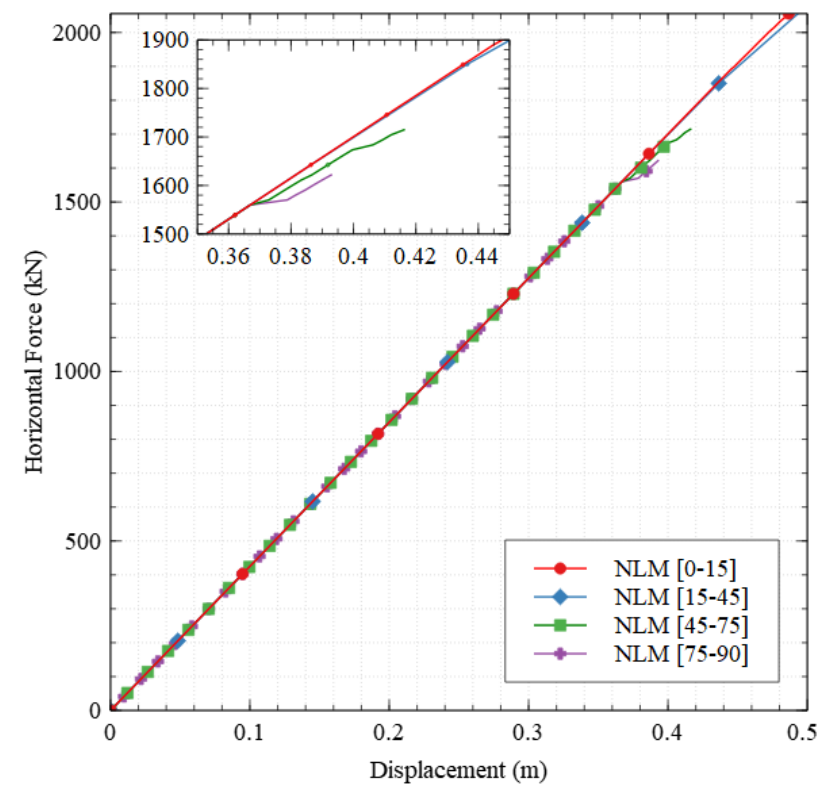

Fig. 3. Fibre orientation comparison. Total horizontal force versus the displacement at the top of the tower.

Up to about $1500 \mathrm{kN}$ all models presented equal linear behaviour since up to this load level they are only submitted to axial loads, therefore no cracking has occurred. After the application of the remaining loads, i.e. wind turbine, direct wind, current and waves forces, the models showed a nonlinear behaviour due to the crack formation.

Note that the models considering fibres oriented at $\left[0-15^{\circ}\right.$ [ and $\left[15-45^{\circ}\right.$ [ presented similar behaviours, with $\left[0-15^{\circ}\right.$ [ performing slightly better. Both models were able to resist the load applied $(\sim 2000 \mathrm{kN})$. The models considering fibre orientations at [45$75^{\circ}$ [ and $\left[75-90^{\circ}\right]$ failed before the application of the total load due to the localization of a failure macro-crack. This behaviour was expected as fibres oriented at such angles do not contribute effectively to increase the concrete tensile strength [12].

For assessing the relative influence of material and geometric nonlinearity on the structural behaviour of the tower being analysed, the following analyses were performed by considering the FRC with tensile properties corresponding to $\left[0-15^{\circ}\right.$ [ fibre orientation interval: i) FRC is considered linear and geometric nonlinearity is not included (LIN); ii) FRC is linear and geometric nonlinearity is included (NLG); iii) FRC is nonlinear and geometric nonlinearity is not considered (NLM); iv) Both types of nonlinearities are considered (NLMG). 


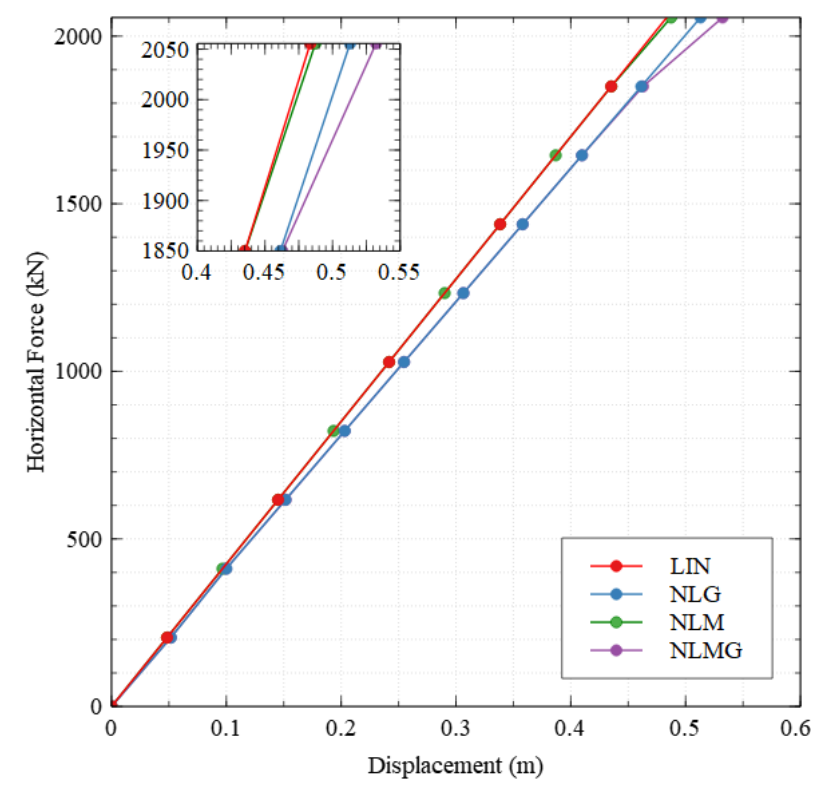

Fig. 4. Effect of material and geometric nonlinearity response of the tower in terms of total horizontal force versus the displacement at the top of the tower.

A simulation considering a plain concrete of the same strength class of FRC was also adopted to analyse the influence of fibre reinforcement. However, no convergence was possible to ensure after crack initiation due to abrupt macro-crack localization. Up to the maximum applied load, the difference between a linear analysis (LIN) and a material nonlinear analysis (NLM) is not significant in terms of maximum lateral deflection, since at this maximum load level the maximum crack width is limited to $0.3 \mathrm{~mm}$. Therefore, due to the reduced crack width of all the cracks formed, the relative loss of stiffness of the tower is marginal. On the other hand, the consideration of the geometric non-linearity increased the displacement at the top of the tower by $6 \%$ (NLG) and $10 \%$ (NLGM).

The last study investigated the effect of reducing the concrete volume (and moment of inertia) of the tower. Two additional analyses were performed. In the first one, the wall thickness of the tower was reduced linearly from top to bottom in 25\% (NLMG25 ) and in the second one, it was reduced in 50\% (NLMG-50). For all models, the radius of the towers was kept the same, i.e. $1.8 \mathrm{~m}$ and $3.6 \mathrm{~m}$ at the top and bottom, respectively. Also, material and geometric nonlinearities were considered and a FRC fibre orientation of $\left[0-15^{\circ}\right.$ [ was used.

The response in terms of horizontal force $v s$ deflection of the towers at the top is compared with the original model (NLMG-00) in Fig. 5. A decrease of the wall thickness in 25\% (NLMG-25) and 50\% (NLMG-50) corresponds to a reduction of concrete volume of, respectively, $23 \%$ and $47 \%$ and in terms of the moment of inertia of $20 \%$ (NLMG-25) and 43\% (NLMG-50). 


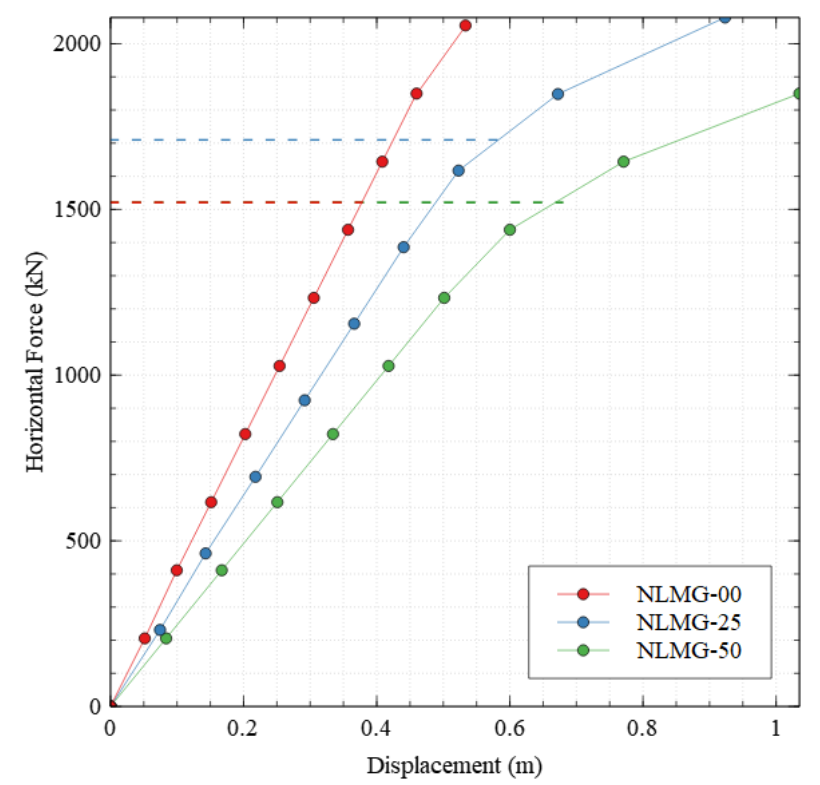

Fig. 5. Effect of the moment of inertia reduction on the behaviour of the tower in terms of total horizontal force versus the displacement at the top of the tower.

Fig. 5 shows that the reduction of wall thickness by $25 \%$ and $50 \%$ increased the displacement at the top of the tower by $73 \%$ and $94 \%$, respectively. The dashed horizontal lines in Fig. 5 indicates the maximum force corresponding to the serviceability limit state combination. According to available research, below to this crack width limit the corrosion of steel fibres, even in maritime environmental conditions, is not sufficient to compromise the structural performance of the SFRC [13].

The stresses $\left(S_{z}\right)$ at the concrete and the crack pattern obtained by the analyses can be seen in Fig. 6. The highest concrete compressive stress is of the order of $32.9 \mathrm{MPa}$ at the tower with a reduction of 50\% (NLMG-50), Fig. 6a. It can also be seen that more cracks are developed by reducing the wall of the structure. However, the number of cracks does not increase significantly when the thickness of the wall is reduced from $25 \%$ to $50 \%$, Fig. 6b. The maximum crack width was $0.2 \mathrm{~mm}(\sim 2055 \mathrm{kN}), 0.3$ $\mathrm{mm}(\sim 2080 \mathrm{kN})$ and $0.4 \mathrm{~mm}(\sim 1850 \mathrm{kN})$ for NLMG-00, NLMG-25 and NLMG-50 respectively. 
Fig. 6. a) Stress $S_{z}$ results in Pa for NLMG-00, NLMG-25 and NLMG-50, respectively. b) Crack pattern for NLMG-00, NLMG-25 and NLMG-50, respectively.

The natural frequencies are also affected by the reduction of volume/moment-ofinertia of the tower. The rotor is the most visible and present source of excitation in a wind turbine system. It creates peaks in excitation at frequencies of the rotor speed range (1P) and blade passing speed range (3P for a three-bladed rotor). Thus, the tower should be designed such that its first natural frequency does not coincide with either $1 \mathrm{P}$ or $3 \mathrm{P}$ excitation to avoid resonance. It is recommended that the lowest frequencies differ from at least $\pm 10 \%$ of the $1 \mathrm{P}$ and $3 \mathrm{P}$ rotor frequencies at nominal power [14].

The frequencies of the towers analysed in the study were calculated using the inhouse FEM-based software for dynamic analysis of frame type structures. The structures were modelled as a cantilever beam with an added mass applied at the top to represent the nacelle and rotor masses. The finite element mesh was made of hundred 2D-Timoshenko beam elements. The estimated first natural frequencies for $0 \%$ (NLM-00), 25\% (NLM-25) and 50\% (NLM-50) of the moment of inertia reduction were $0.338 \mathrm{~Hz}, 0.320 \mathrm{~Hz}$ and $0.289 \mathrm{~Hz}$, respectively. These frequencies do not coincide with either the rotor speed range (1P) or blade passing speed range (3P), which are $0.187 \mathrm{~Hz}$ and $0.560 \mathrm{~Hz}$, respectively. 


\section{Conclusions}

This paper presented the nonlinear finite element analysis of a new concept of offshore wind tower made by prefabricated prestressed fibre reinforced concrete (FRC) segments that are assembled to form the final structure. Three studies were carried out to investigate the impact of the fibre orientation in the FRC, nonlinearities (material and geometric) and moment of inertia of the tower section in the global behaviour of the structure.

The analyses performed clearly showed the importance of considering the geometric and material nonlinearities to analyse this type of structures. The consideration of both nonlinearities increased the displacement at the top of the tower by $10 \%$ at the load level corresponding to serviceability limit design state conditions.

The results obtained in this initial study also indicates the potential of the proposed solution. The analyses showed that, by using fibre reinforcement, it is possible to eliminate conventional passive steel reinforcement and decrease the thickness of the wall of the segments considerably compared to conventional solutions. However, it is necessary to optimise the prefabrication process to guarantee that the fibres are oriented between $0^{\circ}$ and $45^{\circ}$. The influence of the assembling process of the prestressed FRC segments on the global and local (stress gradients in the corresponding connections) behaviour must be also addressed.

\section{Acknowledgements}

This work was supported by FEDER funds through the Operational Programme for Competitiveness and Internationalization - COMPETE and by national funds through FCT - Portuguese Foundation for Science and Technology within the scope of the project InOlicTower - Innovative structural system based on advanced materials for lightweight and durable Offshore Wind Towers, POCI-01-0145-FEDER-016905 (PTDC/ECM-EST/2635/2014).

\section{References}

1. Schaarup, J., Krogh, T.: DNV-Ris $\varnothing$ 'Guidelines for design of wind turbines'. Ris $\varnothing$ vinddag, Denmark. (2002).

2. EFNARC. 2005. The European Guidelines for Self-Compacting Concrete: Specification, Production and Use. UK

3. Abrishambaf, A., Barros, J.A.O., Cunha, V.M.C.F.: Time-dependent flexural behaviour of cracked steel fibre reinforced self-compacting concrete panels. Cement and Concrete Research (72), 21-36, (2015).

4. Abrishambaf, A.: Creep behaviour of cracked steel fibre reinforced self-compacting concrete laminar structures. PhD thesis, University of Minho (2015).

5. Figueiredo, F. P, Hassanabadi, M. E., Barros, J. A. O., Ventura-Gouveia, A.: Simplified Design Approach of Offshore Wind Towers. Report. University of Minho, Portugal (2018) 
6. Arany, L., Bhattacharya, S., Adhikari, S., Hogan, S. J., \& Macdonald, J. H. G.: An analytical Model to Predict the Natural Frequency of Offshore Wind Turbines on Three-Spring Flexible Foundations Using Two Different Beam Models. Soil Dynamics and Earthquake Engineering 74, 40-45 (2015).

7. Ma, H., Yang, J., Chen, L.: Numerical Analysis of the Long-Term Performance of Offshore Wind Turbines Supported by Monopoles. Ocean Engineering 136, 94-105 (2017).

8. DNV: DNV-OS-J101 Design of Offshore Wind Turbine Structures. (2014).

9. Barros, J.A.O.: Debilities and strengths of FEM-based constitutive models for the material nonlinear analysis of steel fiber reinforced concrete structures. In: 9th International Conference on Fracture Mechanics of Concrete and Concrete Structures, FraMCoS-9, V. Saouma, J. Bolander and E. Landis (Eds), California, May 29-June 1, (2016).

10. Gowda, C.C., Figueiredo, F.F, Barros, J.A.O and Ventura-Gouveia, A.: Numerical analyses of the connections between representative SFRC prestressed rings of off-shore wind towers. In: $3^{\text {rd }}$ RILEM Spring Convention, Springer, Portugal, (2020).

11. Ventura-Gouveia, A., "Constitutive models for the material nonlinear analysis of concrete structures including time-dependent effects", PhD thesis, University of Minho, (2011).

12. Lameiras, R.M., Barros, J.A.O., Azenha, M.A.D.: Influence of casting condition on the anisotropy of the fracture properties of Steel Fibre Reinforced Self-Compacting Concrete (SFRSCC). Cement and Concrete Composites (59) 60-76, (2015).

13. Frazão, C.M.V., Barros, J.A.O., Bogas, J.A.B.A.: Durability of Recycled Steel Fiber Reinforced Concrete in Chloride Environment. Fibers Journal, 7(12), (2019).

14. Det Norske Veritas: Guidelines Design of Wind Turbines. $2^{\text {nd }}$ Ed. DNV/Riso, Denmark (2002). 